\title{
Interactive comment on "The DeepMIP contribution to PMIP4: methodologies for selection, compilation and analysis of latest Paleocene and early Eocene climate proxy data, incorporating version 0.1 of the DeepMIP database" by Christopher J. Hollis et al.
}

Christopher J. Hollis et al.

c.hollis@gns.cri.nz

Received and published: 16 June 2019

We appreciate your interest in this important aspect of our study. A preliminary analysis produced a similar GMST estimate for the EECO to that published by Caballero and Huber (2013). However, full characterization of the uncertainty in global mean temperature estimates (surface, SST, LAT) for the latest Paleocene, PETM and EECO is an important research topic in its own right and beyond the scope of this paper. A 
follow-up paper is in preparation on this important topic.

Reference: Caballero, R., and Huber, M.: State-dependent climate sensitivity in past warm climates and its implications for future climate projections, Proceedings of the National Academy of Sciences, doi: 10.1073/pnas.1303365110, 2013.

Interactive comment on Geosci. Model Dev. Discuss., https://doi.org/10.5194/gmd-2018-309, 2019. 